\title{
Spectroscopic studies of Lewis acid-base complexes-VI. Vibrational spectra and normal coordinate calculations for several isotopic varieties of trimethylphosphine-gallium trichloride
}

\author{
David L. W. KwoH* and Robert CoOper TAYlor $\dagger$ \\ Department of Chemistry, The University of Michigan, Ann Arbor, MI 48109, U.S.A.
}

(Received 1 June 1990; accepted 6 September 1990)

\begin{abstract}
Raman and infrared spectra of trimethylphosphine-gallium trichloride have been obtained from microcrystalline solids, mulls and $\mathrm{KBr}$ discs. The data include results from the deuterated species as well as from samples prepared from ${ }^{69} \mathrm{Ga}$ and ${ }^{71} \mathrm{Ga}$. Revised assignments are proposed on the basis of the isotopic data and are supported by normal coordinate calculations.
\end{abstract}

\section{INTRODUCTION}

AMONG the various molecular properties which have been employed as indices of dative bond strength in Lewis acid-base complexes, force constants have been one of the most frequently used. Although pronounced changes may occur in some of the internal force constants of the acid and base moieties upon complexation, most attention has focussed on the dative bond force constant. To date, attempts at correlating this constant with the acid or base strength, as determined from chemical data, of the participating partners have not been particularly successful. In some cases the difference in this force constant between two complexes has scarcely been more than the uncertainties involved, despite marked differences in the stability of the complexes being compared. Clearly, the relationships of the various variables involved have not been fully delineated and further study of Lewis complexes is needed.

Many of the detailed investigations that have been made to date have involved acids or bases of first row elements where steric crowding has been present in the complex [1]. In the present investigation of trimethylphosphine-gallium trichloride, this factor is minimal, so much so that the complex has the unusual eclipsed configuration in the solid state where, presumably, intermolecular packing considerations have overcome intramolecular effects [2]. This absence of intramolecular steric effects may be informative in comparing results from various complexes.

Previous spectroscopic work on the trimethylphosphine-gallium trichloride complex consists of three papers [3-5]. The first two are limited in scope and give i.r. frequencies primarily for purposes of characterization. The third [5] reports both i.r. and Raman data together with the results of a normal coordinate analysis. However, the data were obtained for the normal compound only, no data for isotopic compounds being presented, and Raman polarization measurements were not feasible. Spectroscopic studies for the related complexes, phosphine-gallium trichloride and triphenylphosphine-gallium trichloride, have appeared recently $[6,7]$ but the data again are limited to the normal species. The present investigation extends the data for trimethylphosphine-gallium trichloride to include those for the deuterated species and also provides results for complexes containing isotopically enriched ${ }^{69} \mathrm{Ga}$ and ${ }^{71} \mathrm{Ga}$. A normal coordinate analysis has been carried out to confirm revised assignments. For several modes, the calculations indicated a sufficient difference between $A_{1}$ and $E$ isotope shifts to enable symmetry assignments to be made with some degree of confidence.

\footnotetext{
* Present address: Unilever Research U.S.A., Inc., Edgewater, New Jersey, U.S.A.

$\dagger$ Author to whom correspondence should be addressed.
} 


\section{EXPERIMENTAL}

Due to the very reactive nature of the compounds involved, all preparative work was performed in a conventional high vacuum system equipped wherever possible with Teflon stopcocks. Natural anhydrous gallium chloride obtained from the Alfa Division of the Ventron Corporation was sublimed in vacuo before use. Isotopically enriched ${ }^{69} \mathrm{Ga}$ and ${ }^{71} \mathrm{Ga}$ with stated isotopic purities in excess of $99 \%$ were obtained from the Oak Ridge National Laboratory in the form of $\mathrm{Ga}_{2} \mathrm{O}_{3}$. The oxides were converted to the anhydrous chlorides by heating them in a slow stream of dry nitrogen saturated with $\mathrm{CCl}_{4}$ at $500^{\circ} \mathrm{C}$. The collected product was then resublimed. Trimethylphosphine was prepared by the method described by JoLLY [8] which involves stepwise methylation of phosphine by methyl iodide. The deuterated species $\mathrm{PD}_{3}$ was prepared from heavy water and calcium phosphide and methylated with $\mathrm{CD}_{3} \mathrm{I}$. Although the deuterium content of the starting materials was in excess of $99.5 \%$, some exchange occurred during synthesis such that it was estimated that the deuteromethyl groups in the final product contained about $3 \%$ hydrogen. For both the normal and deuterated species, the absence of dimethylphosphine in the final product was checked by i.r. methods.

It was found that the best method of preparation of the complexes was by direct reaction of the pure acid and base. In practice, excess trimethylphosphine was condensed on the gallium trichloride at liquid nitrogen temperatures and the mixture allowed to warm gradually. Excess trimethylphosphine was then removed by evacuation, the yield being essentially quantitative. Failure to use an excess of the phosphine resulted in an unusable product. Confirmation of the composition of the complexes was by elemental analysis and mass spectral data.

Infrared spectra were obtained from Nujol or Fluorolube mulls, or $\mathrm{KBr}$ discs. Although all samples for spectroscopic examination were prepared in a controlled dry nitrogen atmosphere box, the use of the $\mathrm{KBr}$ pelleting technique was not entirely satisfactory. It was difficult to remove the last traces of adsorbed water from the $\mathrm{KBr}$ and it was necessary to expose the $\mathrm{KBr}$ mixture to the atmosphere during the pressing process. Unfortunately, the phosphorus in the complexes has a strong affinity for oxygen resulting in a slow reaction of the complex with oxygen upon exposure to air to give structures containing the $\mathrm{R}-\mathrm{O}-\mathrm{P}$ group. The presence of such impurities could be detected by the presence of a band near $1020 \mathrm{~cm}^{-1}$ [9] whose intensity became substantial if the exposure continued for any period of time. The presence of an oxygen containing impurity was confirmed by the mass spectral data of samples that had been exposed to air. The band in question was eliminated by preparing mulls in a nitrogen atmosphere and by recording the spectra while the samples were contained in an evacuated cell. For the Raman work, powdered (microcrystalline) samples were sealed in $2 \mathrm{~mm}$ capillary tubes under nitrogen. No difficulties were encountered with fluorescence. No solvent was found in which the complexes were soluble and stable, and consequently it was not possible to make polarization measurements of Raman bands.

Spectroscopic equipment included a Beckman 4240 spectrometer for the $4000-250 \mathrm{~cm}^{-1}$ region, a Digilab FTS-16 FTIR for the far-i.r. region $\left(400-30 \mathrm{~cm}^{-1}\right)$ and a Spex 1401 Ramalog for the Raman spectra. Resolution was approximately $2 \mathrm{~cm}^{-1}$ for all instuments; although the precision with which band maxima could be measured was of the order of $0.2-0.5 \mathrm{~cm}^{-1}$, a realistic assessment of uncertainties gives values closer to $1-2 \mathrm{~cm}^{-1}$.

\section{EXPERimental Results AND Assignments}

Observed i.r. and Raman frequencies for the normal and deuterated species are listed in Table 1, and values for the fundamentals of the normal and deuterated species, together with calculated frequencies, and the gallium isotope shifts are listed in Table 2. The experimental frequencies in this table represent a composite of best values for the fundamentals arrived at by considering all data and the precision of the various measurements. The numbering scheme and a qualitative description of the fundamentals is given in Table 3. Raman spectra for the normal and deuterated species are shown in Figs 1 and 2, and the far-i.r. spectrum of the deuterated species is shown in Fig. 3.

Although the site symmetry of the $\left(\mathrm{CH}_{3}\right)_{3} \mathrm{PGaCl}_{3}$ molecule in the crystal is $C_{s}$ [2], only two or three instances of possible crystal splittings were observed with the resolution used, and the magnitudes of these were small. To simplify the analysis, therefore, the molecule was assumed to have effectively $C_{3 v}$ symmetry. The vibrational structure for this symmetry is $10 A_{1}+5 A_{2}+15 E$ with the $A_{1}$ and $E$ modes being allowed in Raman and 
Table 1. Observed vibrational frequencies (in $\mathrm{cm}^{-1}$ ) for normal and deuterated trimethyphosphine-gallium trichloride

\begin{tabular}{|c|c|c|c|c|c|c|}
\hline \multicolumn{2}{|c|}{$\begin{array}{l}\left(\mathrm{CH}_{3}\right)_{3} \mathrm{P}: \mathrm{GaCl}_{3} \\
\text { Infrared }\end{array}$} & \multirow{2}{*}{$\begin{array}{l}\text { Raman } \\
\text { solid }\end{array}$} & \multicolumn{2}{|c|}{$\begin{array}{l}\left(\mathrm{CD}_{3}\right)_{3} \mathrm{P}: \mathrm{GaCl}_{3} \\
\text { Infrared }\end{array}$} & \multirow{2}{*}{$\begin{array}{l}\text { Raman } \\
\text { solid }\end{array}$} & \multirow[b]{2}{*}{ Assignment } \\
\hline KBr Disc & Nujol mull & & KBr Disc & Nujol mull & & \\
\hline & & & 2251.8 & 2252.0 & & \\
\hline 2999.3 & & & 2246.3 & 2247.8 & & \\
\hline 2993.4 & & & 2243.7 & 2243.7 & & $\nu_{1}, v_{16}, v_{17}$ \\
\hline 2981.3 & & & 2237.8 & 2237.7 & & \\
\hline 2918.3 & & & 2134.0 & 2134.0 & & $\nu_{2}, v_{18}$ \\
\hline 2910.0 & & & 2130.0 & 2130.0 & & \\
\hline $1433.6 \mathrm{w}$ & & $1434.2 \mathrm{w}$ & & & & $v_{6}+v_{24}$ \\
\hline $1422.0 \mathrm{~s}$ & $1423.5 \mathrm{~s}$ & $1423.7 \mathrm{w}$ & $1034.4 \mathrm{~s}$ & $1034.0 \mathrm{~s}$ & $1034.1 \mathrm{w}$ & $v_{3}$ \\
\hline $1416.0 \mathrm{~s}$ & $1417.5 \mathrm{~s}$ & $1414.0 \mathrm{w}$ & $1021.5 \mathrm{~s}$ & $1020.7 \mathrm{~s}$ & $1020.3 w$ & $v_{19}$ \\
\hline $1410.0 \mathrm{~s}$ & $1411.5 \mathrm{~s}$ & & 1040.2 & 1040.2 & 1041.9 & $?$ \\
\hline $1401.9 w$ & $1402.4 \mathrm{w}$ & 1403.3 & $1016.5 \mathrm{~s}$ & $1016.0 \mathrm{~s}$ & $1017.0 \mathrm{w}$ & $v_{20}$ \\
\hline \multicolumn{7}{|l|}{$1384.4 \mathrm{w}$} \\
\hline $1343.8 w$ & $1345.4 \mathrm{w}$ & & & & & $2 v_{6}$ \\
\hline $1317.5 w$ & $1318.5 \mathrm{w}$ & & & & & \\
\hline $1311.4 \mathrm{~m}$ & $1311.7 \mathrm{~m}$ & & $971.0 \mathrm{w}$ & & & $v_{21}$ \\
\hline $1299.3 w$ & $1298.7 w$ & & & & & \\
\hline $1293.8 \mathrm{~s}$ & $1292.8 \mathrm{~s}$ & $1293.0 \mathrm{w}$ & 957.3 & $956.4 \mathrm{w}$ & & $v_{4}$ \\
\hline $1018.0 \mathrm{w}$ & & & & & & R-O-P Impurity \\
\hline $1011.6 \mathrm{w}$ & $1013.0 \mathrm{w}$ & & & & & $v_{6}+v_{8}$ \\
\hline $1006.4 \mathrm{w}$ & $1006.2 \mathrm{w}$ & & & & & \\
\hline $972.3 \mathrm{~s}$ & $973.4 \mathrm{~s}$ & $969.7 \mathrm{w}$ & & & & $v_{24}+v_{28}$ \\
\hline $957.4 \mathrm{~s}$ & $958.3 \mathrm{~s}$ & $956.5 \mathrm{w}$ & $689.4 w$ & $689.4 w$ & $692.6 \mathrm{~s}$ & $v_{22}$ \\
\hline $928.4 \mathrm{w}$ & $929.4 \mathrm{w}$ & & $857.0 \mathrm{w}$ & $854.7 w$ & & $v_{5}$ \\
\hline $856.5 \mathrm{~m}$ & $854.1 \mathrm{~m}$ & $852.9 \mathrm{w}$ & & $639.2 w$ & $640.5 \mathrm{w}$ & $v_{23}$ \\
\hline $848.3 \mathrm{~m}$ & $848.2 \mathrm{~m}$ & $847.5 w$ & & & & \\
\hline \multirow[t]{2}{*}{$785.8 \mathrm{w}$} & $784.4 \mathrm{w}$ & & & & & \\
\hline & & 793.1 & & & & \\
\hline $781.3 w$ & $780.3 w$ & & & & & \\
\hline $762.7 \mathrm{~s}$ & $\begin{array}{l}762.3 \mathrm{~s} \\
724.0 \mathrm{~m}\end{array}$ & $763.6 \mathrm{~s}$ & $787.0 \mathrm{~s}$ & $\begin{array}{l}786.4 \mathrm{~s} \\
723.0 \mathrm{~m}\end{array}$ & $790.6 w$ & $\begin{array}{l}\boldsymbol{v}_{24} \\
\text { Nujol }\end{array}$ \\
\hline $674.0 \mathrm{w}$ & & $673.0 \mathrm{~s}$ & $607.2 \mathrm{w}$ & $608.3 w$ & $\begin{array}{l}607.3 \mathrm{~s} \\
383.4 \mathrm{w}\end{array}$ & $v_{6}$ \\
\hline \multirow[t]{3}{*}{$378.5 \mathrm{~s}$} & $380.0 \mathrm{~s}$ & 379.8 & $374.0 \mathrm{~s}$ & $378.0 \mathrm{~s}$ & 372.1 & $v_{25}$ \\
\hline & & $369.6 \mathrm{w}$ & & & 361.2 & $v_{7}$ \\
\hline & & $347.1 \mathrm{w}$ & & & & $\nu_{9}+v_{31}$ \\
\hline \multirow[t]{13}{*}{$336.7 \mathrm{~s}$} & $340.0 \mathrm{~s}$ & $337.7 \mathrm{~s}$ & & $321.5 \mathrm{~s}$ & $322.6 \mathrm{~s}$ & $v_{8}$ \\
\hline & $259.0 \mathrm{w}$ & $261.5 \mathrm{~m}$ & & $223.5 \mathrm{w}$ & 223.5 & $v_{y}$ \\
\hline & $256.0 \mathrm{w}$ & $257.7 \mathrm{sh}$ & & $219.0 \mathrm{w}$ & $220.3 \mathrm{sh}$ & \\
\hline & $212.5 \mathrm{w}$ & & & $159.0 \mathrm{~s}$ & 151.1 & $\nu_{2 \mathrm{~K}}$ \\
\hline & & $207.7 \mathrm{~m}$ & & $170.0 \mathrm{w}$ & $169.6 \mathrm{~s}$ & $\nu_{27}^{-17}$ \\
\hline & $186.0 \mathrm{w}$ & $182.2 \mathrm{~m}$ & & $193.7 \mathrm{~m}$ & $188.2 \mathrm{~m}$ & $v_{2 k}$ \\
\hline & $152.2 \mathrm{~s}$ & $143.0 \mathrm{~s}$ & & $149.0 \mathrm{~s}$ & 142.3 & $v_{29}$ \\
\hline & $130.5 \mathrm{~s}$ & $133.8 \mathrm{~s}$ & & $128.0 \mathrm{~s}$ & $126.9 \mathrm{~m}$ & $\nu_{10}$ \\
\hline & & $101.3 \mathrm{w}$ & & 96.5 & 97.3 & \\
\hline & $95.0 \mathrm{w}$ & $93.3 w$ & & & $90.2 \mathrm{~m}$ & $v_{30}$ \\
\hline & & & & $83.0 \mathrm{w}$ & & \\
\hline & $77.5 \mathrm{~m}$ & & & $74.0 \mathrm{~m}$ & & \\
\hline & $60.5 \mathrm{~m}$ & & & $59.4 \mathrm{~m}$ & & \\
\hline
\end{tabular}

i.r. spectra and the $A_{2}$ modes forbidden in both. For purposes of discussion, the fundamentals can be divided into several groups, viz, the methyl stretching frequencies and methyl deformation frequencies, the $\mathrm{P}-\mathrm{C}_{3}$ skeletal modes and the motions associated with the $\mathrm{GaCl}_{3}$ part of the molecule. Since polarization data were not available, some symmetry designations remain equivocal. However, the normal coordinate calculations were useful in several cases where the magnitude of the calculated isotopic shift differed significantly between the two classes. 
Table 2. Fundamental frequencies (in $\left.\mathrm{cm}^{-1}\right)$ for $\left(\mathrm{CH}_{3}\right)_{3} \mathrm{P}: \mathrm{GaCl}_{3}$ and $\left(\mathrm{CD}_{3}\right)_{3} \mathrm{P}: \mathrm{GaCl}_{3}$, calculated values and ${ }^{69} \mathrm{Ga}-{ }^{71} \mathrm{Ga}$ isotope shifts

\begin{tabular}{|c|c|c|c|c|c|c|}
\hline \multirow[b]{2}{*}{ Fundamental } & \multicolumn{2}{|c|}{$\left(\mathrm{CH}_{3}\right)_{3} \mathrm{P}: \mathrm{GaCl}_{3}$} & \multicolumn{2}{|c|}{$\left(\mathrm{CD}_{3}\right)_{3} \mathrm{P}: \mathrm{GaCl}_{3}$} & \multicolumn{2}{|c|}{${ }^{69} \mathrm{Ga}-{ }^{71} \mathrm{Ga}$ Shifts } \\
\hline & Exp. & Calc. & Exp. & Calc. & Exp. & Calc \\
\hline \multicolumn{7}{|l|}{$A_{1}$ Class } \\
\hline$v_{1}$ & 2995.0 & 2996.2 & 2250.0 & 2240.9 & 0.0 & 0.0 \\
\hline$v_{2}$ & 2914.0 & 2921.6 & 2130.0 & 2099.9 & 0.0 & 0.0 \\
\hline$v_{3}$ & 1422.8 & 1420.3 & 1034.1 & 1039.0 & 0.2 & 0.0 \\
\hline$v_{4}$ & 1293.4 & 1292.9 & 959.0 & 958.8 & 0.5 & 0.0 \\
\hline$v_{5}$ & 928.4 & 928.5 & 854.7 & 853.9 & 4.0 & 0.1 \\
\hline$v_{6}$ & 673.5 & 673.1 & 607.8 & 606.5 & 2.0 & 0.1 \\
\hline$v_{7}$ & 369.6 & 371.3 & 361.2 & 357.8 & 1.8 & 1.5 \\
\hline$v_{8}$ & 338.9 & 339.4 & 322.1 & 319.7 & -0.1 & 0.0 \\
\hline$v_{4}$ & 256.8 & 257.1 & 219.6 & 218.1 & -0.8 & 1.3 \\
\hline$v_{10}$ & 133.5 & 133.2 & 126.9 & 129.0 & 0.0 & 0.1 \\
\hline \multicolumn{7}{|l|}{$E$ Class } \\
\hline$v_{16}$ & 2999.0 & 3001.2 & 2252.0 & 2257.2 & 0.0 & 0.0 \\
\hline$\nu_{17}$ & 2981.0 & 2980.5 & 2244.0 & 2234.2 & -1.0 & 0.0 \\
\hline$v_{18}$ & 2918.0 & 2925.1 & 2134.0 & 2102.6 & 0.0 & 0.0 \\
\hline$v_{19}$ & 1413.5 & 1414.8 & 1020.5 & 1027.5 & 0.4 & 0.0 \\
\hline$v_{21}$ & 1402.6 & 1399.0 & 1016.5 & 1010.4 & 0.5 & 0.0 \\
\hline$\nu_{21}$ & 1311.4 & 1314.9 & 973.5 & 969.2 & 0.6 & 0.0 \\
\hline$\nu_{22}$ & 956.9 & 956.4 & 691.0 & 690.9 & -0.8 & 0.0 \\
\hline$\nu_{23}$ & 851.3 & 854.9 & 639.8 & 631.6 & -0.1 & 0.0 \\
\hline$v_{24}$ & 763.2 & 766.9 & 788.5 & 781.8 & 0.3 & 0.0 \\
\hline$v_{2 s}$ & 379.8 & 377.6 & 377.2 & 377.1 & 1.2 & 2.6 \\
\hline$v_{36}$ & 184.1 & 183.7 & 188.2 & 189.7 & 0.0 & 0.2 \\
\hline$v_{27}$ & 207.7 & 206.8 & 169.6 & 169.7 & 0.4 & 0.1 \\
\hline$v_{28}$ & 210.1 & 208.9 & 151.1 & 147.8 & - & 0.0 \\
\hline$v_{29}$ & 142.2 & 142.9 & 142.3 & 139.9 & 0.3 & 0.1 \\
\hline$v_{310}$ & 94.1 & 94.0 & 90.3 & 88.9 & 0.3 & 0.1 \\
\hline
\end{tabular}

Product rule ratios $(H / D)$ :

$$
\begin{array}{ll}
A_{1} \text { Class Theor. }=5.547 & \text { Exp. }=5.549(-0.04 \%) \\
E \text { Class Theor. }=21.144 & \text { Exp. }=19.382(8.3 \%) .
\end{array}
$$

\begin{tabular}{|c|c|c|c|}
\hline Mode & Description & Mode & Description \\
\hline$A_{1}$ Class & & $E$ Class & \\
\hline$v_{1}$ & Asymmetric* $\mathrm{C}-\mathrm{H}$ stretch & $v_{16}$ & Asymmetric $\mathrm{C}-\mathrm{H}$ stretch \\
\hline$v_{2}$ & Symmetric $\mathrm{C}-\mathrm{H}$ stretch & $v_{17}$ & Asymmetric C-H stretch \\
\hline$v_{3}$ & Asymmetric $\mathrm{CH}_{3}$ deformation & $\nu_{18}$ & Symmetric C-H stretch \\
\hline$\nu_{4}$ & Symmetric $\mathrm{CH}_{3}$ deformation & $v_{14}$ & Asymmetric $\mathrm{CH}_{3}$ deformation \\
\hline$v_{5}$ & Methyl group rock & $v_{20}$ & Symmetric $\mathrm{CH}_{3}$ deformation \\
\hline$v_{h}$ & P-C Stretch & $\nu_{21}^{-11}$ & Asymmetric $\mathrm{CH}_{3}$ deformation \\
\hline$v_{7}$ & Ga-P Stretch & $\nu_{22}$ & Methyl group rock \\
\hline$v_{x}$ & $\mathrm{Ga}-\mathrm{Cl}$ Stretch & $\nu_{23}$ & Methyl group wag \\
\hline$v_{9}$ & $\mathrm{PC}_{3}$ Deformation & $\nu_{24}$ & P-C Stretch \\
\hline \multirow[t]{2}{*}{$v_{10}$} & $\mathrm{GaCl}_{3}$ Deformation & $v_{25}$ & Ga-Cl Stretch \\
\hline & & $v_{26}$ & $\mathrm{PC}_{3}$ Rock \\
\hline$A_{2}$ Class & & $v_{27}$ & $\mathrm{PC}_{3}$ Deformation \\
\hline$v_{11}$ & Asymmetric $\mathrm{C}-\mathrm{H}$ stretch & $v_{2 \mathrm{~K}}$ & Methyl group torsion \\
\hline$v_{12}$ & Asymmetric $\mathrm{CH}_{3}$ deformation & $\nu_{2 y}$ & $\mathrm{GaCl}_{3}$ Deformation \\
\hline$v_{1.3}$ & Methyl group wag & $\nu_{m !}$ & GaCl Rock \\
\hline$v_{14}$ & Methyl group torsion & & \\
\hline$\nu_{15}$ & Torsion around $\mathrm{Ga}-\mathrm{P}$ bond & & \\
\hline
\end{tabular}

Table 3. Numbering and description of fundamental modes of $\left(\mathrm{CH}_{3}\right)_{3} \mathrm{P}: \mathrm{GaCl}_{3}$

* Asymmetric and Symmetric refer to the internal symmetry of the $\mathrm{CH}_{3}$ groups. 
Frequencies associated with the methyl groups in trimethylphosphine, alone and in complexes, have been well identified in other investigations [5,9-12]. The stretching modes occur in the $2900-3020 \mathrm{~cm}^{-1}$ region for the normal species and shift to $2100-2250 \mathrm{~cm}^{-1}$ upon deuteration. Raman polarization studies $[10,11]$ for the normal and deuterated species of free trimethylphosphine show the higher frequencies to be depolarized and the lower to be polarized. Since the $\mathrm{C}-\mathrm{H}$ frequencies are the least likely to be affected by complexation, the three modes involving internal asymmetric stretchings within the methyl groups are assigned to bands in the interval $2970-3010 \mathrm{~cm}^{-1}$, shifting to $2220-2250 \mathrm{~cm}^{-1}$. Similarly, the two modes in which the local methyl group symmetry is preserved are assigned to the range $2890-2920 \mathrm{~cm}^{-1}$, shifting to $2115-2135 \mathrm{~cm}^{-1}$. These $\mathrm{C}-\mathrm{H}$ stretching bands were of secondary interest in the present study, and since Fermi resonances with the deformation modes undoubtedly are present, the specific assignments of Table 2 cannot be considered final. The deviation of the product rule ratios shown in Table 2 from more generally accepted values is attributed to these resonance effects.

As in the case of the stretching frequencies, there are three $E$ and two $A_{1}$ methyl deformation modes. These likewise can be given qualitative descriptions in terms of the local symmetry of the methyl groups. Three clearly delineated bands were observed in both the i.r. and Raman spectra in the region $1400-1425 \mathrm{~cm}^{-1}$ which shifted to $1015-1035 \mathrm{~cm}^{-1}$ upon deuteration. Although all three might be expected to arise from motions in which the local 3-fold axis of the methyl group is destroyed, the normal coordinate calculations consistently put one of the $E$ asymmetric deformations $\left(\nu_{21}\right)$ in the vicinity of $1300 \mathrm{~cm}^{-1}$ and the symmetric $E$ motion $\left(v_{20}\right)$ near $1400 \mathrm{~cm}^{-1}$. In the absence of polarization data, more specific assignments within the $1400 \mathrm{~cm}^{-1}$ group must be regarded as arbitrary. Two bands were observed in the lower deformation region at 1311 and $1293 \mathrm{~cm}^{-1}$. The $A_{1}$ symmetric deformation mode is assigned to the band at $1290 \mathrm{~cm}^{-1}$ shifting to $959 \mathrm{~cm}^{-1}$.

Wagging and rocking motions of methyl groups in related compounds have been assigned in the general range from about 800 to $950 \mathrm{~cm}^{-1}[9-11,13]$. Accordingly, the band at $928 \mathrm{~cm}^{-1}$ in the normal species is assigned to the $A_{1}$ rocking mode and the bands at 957 and $851 \mathrm{~cm}^{-1}$ to the $E$ rocking modes. These assignments agree well with assigned bands in the spectra of trimethylphosphine oxide $[11,19]$, which contains a tetracoordinate phosphorus with three methyl groups attached, as well as with the predictions by the empirical expression of TANAKA and GOTOH [14]. Deuterium substitution shifted the $A_{1}$ band by only $74 \mathrm{~cm}^{-1}$ to $855 \mathrm{~cm}^{-1}$ while the two $E$ modes shifted by more than $200 \mathrm{~cm}^{-1}$. These shifts were confirmed by the normal coordinate analysis. The remaining methyl group motion is the $E$ species torsional mode which has been assigned to a band at $210 \mathrm{~cm}^{-1}$, shifting to $151 \mathrm{~cm}^{-1}$ upon deuteration. There are two other bands in the general vicinity of $200 \mathrm{~cm}^{-1}$ which might have been assigned to the torsional mode. One, however, was observed only in the Raman spectrum in which torsions usually are weak, and the other did not show a large enough deuterium shift.

The $E$ and $A_{1} \mathrm{P}-\mathrm{C}$ stretching modes are assigned, respectively, to bands at 763 and $673 \mathrm{~cm}^{-1}$ for the hydrogen species. These values are in good agreement with corresponding assignments for $\left(\mathrm{CH}_{3}\right)_{3} \mathrm{P}: \mathrm{BX} \mathrm{X}_{3}$ complexes [10] and for the $\left(\mathrm{CH}_{3}\right)_{3} \mathrm{P}: \mathrm{X}$ series $[11,19]$

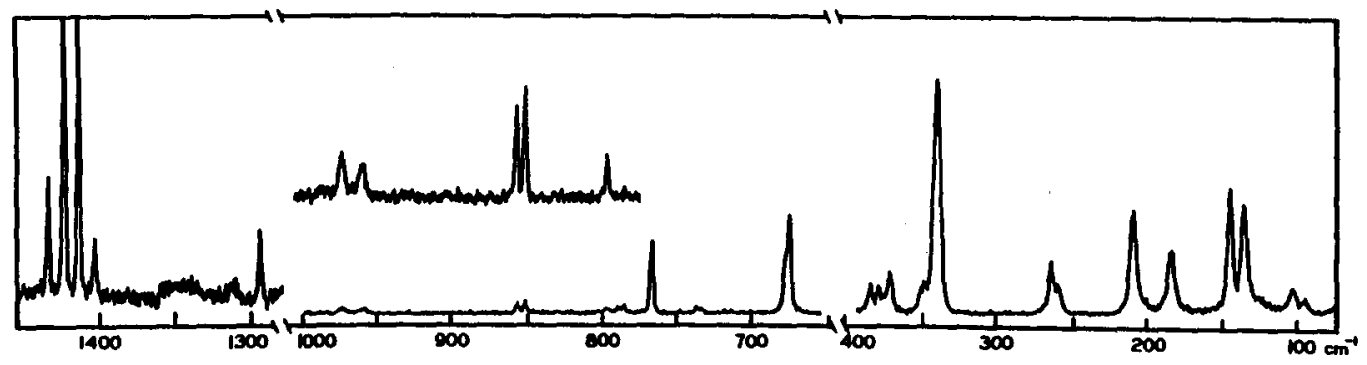

Fig. 1. Raman spectrum of solid trimethylphosphine-gallium trichloride. 


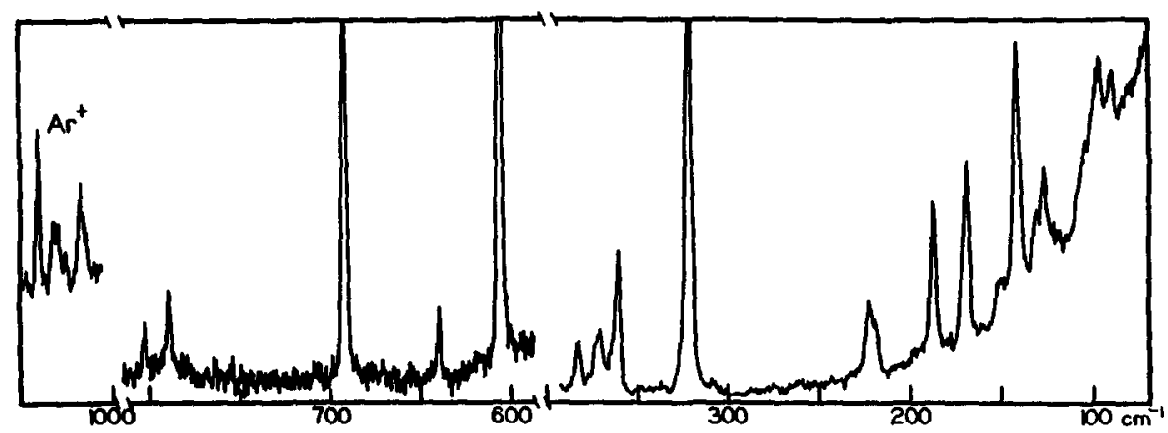

Fig. 2. Raman spectrum of solid trimethylphosphine-gallium trichloride- $d_{\mathrm{q}}$.

where $\mathrm{X}=\mathrm{O}, \mathrm{S}$ and Se. Upon deuteration, the $A_{1}$ band at $673 \mathrm{~cm}^{-1}$ shifted to $608 \mathrm{~cm}^{-1}$, again in good agreement with the above references. However, the $E$ mode is assigned to a band at $788 \mathrm{~cm}^{-1}$, a higher rather than lower value than for the hydrogen species. This unusual isotope shift was confirmed by the results of the normal coordinate analysis which consistently put the $\mathrm{P}-\mathrm{C}$ stretch at that position. It can be rationalized by noting that upon deuterium substitution, the two $E$ methyl group rocking motions, which both have higher frequencies than the $\mathrm{P}-\mathrm{C}$ stretch in the hydrogen molecule, exhibit substantial shifts and move below the $\mathrm{P}-\mathrm{C}$ mode. The well known repelling effect between levels of like symmetry must therefore be responsible for the $\mathrm{P}-\mathrm{C}$ stretch shifting to higher frequency in the deuterium species.

The remaining modes associated with the $\mathrm{PC}_{3}$ skeleton are the two $\mathrm{PC}_{3}$ deformations and the $E$ species $\mathrm{PC}_{3}$ rock. These fundamentals may be expected to occur in the general region between 150 and $300 \mathrm{~cm}^{-1}$ and bands at 257,208 and $184 \mathrm{~cm}^{-1}$, on the basis of their deuterium shifts, appear to be the best candidates. The methyl torsional mode, which also occurs in this region, has been assigned previously. In trimethylphosphine itself, Raman polarization data $[10,12,15]$ have fairly conclusively established that the symmetric $\mathrm{PC}_{3}$ deformation mode occurs at a higher frequency than the asymmetric, the separation being approximately $40 \mathrm{~cm}^{-1}$. This separation persists in the deuterated species. Data from Raman spectra of solutions [16] and single crystals [11,19] of $\left(\mathrm{CH}_{3}\right)_{3} \mathrm{PX}$ compounds $(\mathrm{X}=\mathrm{O}, \mathrm{S}, \mathrm{Se})$ indicate that the same order and separation occurs in those compounds. Other trimethylphosphine complexes whose spectra have been reported have all been in the solid state and, in the absence of definitive symmetry information, no consistent pattern of assignment has been noted. In the present case, the bands at 257 and $208 \mathrm{~cm}^{-1}$ have been assigned to the $A_{1}$ and $E$ deformations, respectively. They shift to 220 and $170 \mathrm{~cm}^{-1}$ upon deuteration. The remaining band at $184 \mathrm{~cm}^{-1}$ is attributed to the $E$ rocking mode. Upon deuteration, it shifts slightly up in frequency

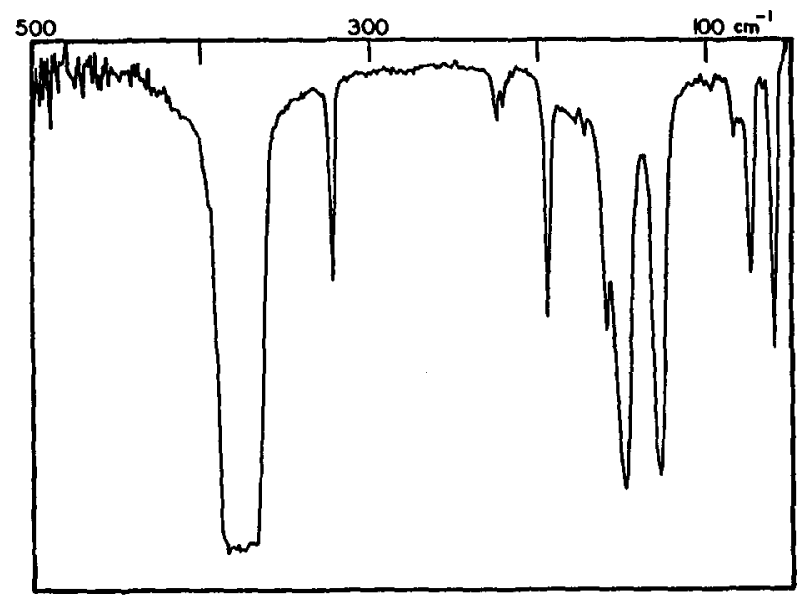

Fig. 3. Far-i.r. spectrum of solid trimethylphosphine- $d_{4}$ gallium trichloride (mull). 
to $188 \mathrm{~cm}^{-1}$, again because of the interaction with the methyl torsion and the $\mathrm{PC}_{3}$ deformation which occur at lower frequencies in the deuterated molecule.

The modes associated with the gallium trichloride part of the molecule include the dative bond stretch $\nu_{7}$, the two $\mathrm{Ga}-\mathrm{Cl}$ stetching modes $v_{8}$ and $v_{25}$, the $\mathrm{GaCl}_{3}$ deformations $\nu_{10}$ and $\nu_{29}$, and the $\mathrm{GaCl}_{3}$ rock, $\nu_{30}$. The dative bond frequency, $\nu_{7}$, was assigned in the earlier work [5] to the band at $380 \mathrm{~cm}^{-1}$. However, the absence of polarization data renders the choice equivocal in view of the other bands in the vicinity. We have chosen to assign the band at $370 \mathrm{~cm}^{-1}$ to the dative bond frequency and the $380 \mathrm{~cm}^{-1}$ band to $v_{25}$, the $E$ species $\mathrm{Ga}-\mathrm{Cl}$ stretching mode, on the basis of observed vs calculated deuterium shifts. The normal coordinate calculations predict a $13.5 \mathrm{~cm}^{-1}$ shift for $\nu_{7}$ and only a $0.5 \mathrm{~cm}^{-1}$ shift for $v_{25}$ which may be compared with the observed shifts of 8.4 and $2.6 \mathrm{~cm}^{-1}$ for the 370 and $380 \mathrm{~cm}^{-1}$ bands, respectively. We have assigned the band at $339 \mathrm{~cm}^{-1}$ to $\nu_{8}$, the $A_{1} \mathrm{Ga}-\mathrm{Cl}$ mode. Its observed deuterium shift is about $17 \mathrm{~cm}^{-1}$ compared to the calculated value of $20 \mathrm{~cm}^{-1}$. The experimental ${ }^{69} \mathrm{Ga}-{ }^{71} \mathrm{Ga}$ shifts compare well with those calculated for $\nu_{7}$ and $\nu_{25}$ while both the observed and calculated shifts for $\nu_{8}$ are negligible.

The two $\mathrm{GaCl}_{3}$ deformation modes are assigned to bands at 142 and $133 \mathrm{~cm}^{-1}$ for the $E$ and $A_{1}$ species, respectively, in agreement with previous assignments $[5,7]$. This order agrees with the normal coordinate calculations which show a stronger deuterium effect for the $A_{1}$ band than for the $E$. Finally, the $\mathrm{GaCl}_{3}$ rocking mode is assigned to the band at $94 \mathrm{~cm}^{-1}$ in agreement with prevous work [5] and also with the observed and calculated isotope shifts.

\section{Normal Coordinate Calculations}

Normal coordinate calculations were carried out using a standard least squares procedure which has been described previously [16]; symmetry force constants in each symmetry class were the parameters which were fitted. G matrix elements were calculated from the $\mathrm{X}$-ray parameters [2], and the symmetry coordinates used were based on those given in Ref. [17] except that the necessary coefficients for the angles around the $\mathrm{Ga}$ and $\mathrm{P}$ atoms were inserted in the expressions for $S_{9}$ and $S_{10}$ to take into account the fact that the angles around those atoms were not tetrahedral. (See, for example, Ref. [18].) Experimental frequencies for all isotopic species in a given symmetry class were fitted simultaneously. Attempts were made initially to use compliance constants rather than force constants, as has been done in earlier papers in this series [16]; however, convergence problems were encountered which did not seem to be present when the problem was approached through force constants. The reason for these difficulties was not pursued but may have been due to a poor choice of starting values for the constants.

For the $A_{1}$ class, five off-diagonal constants in addition to the ten diagonal were sufficient to give an average deviation between observed and calculated frequencies of $2.6 \mathrm{~cm}^{-1}(0.31 \%)$. Considering that the $\mathrm{C}-\mathrm{H}$ stretching frequencies were included, this was quite satisfactory. For the $E$ class, nine off-diagonal constants were needed and the average deviation of the fitted frequencies was $3.2 \mathrm{~cm}^{-1}(0.46 \%)$, again quite satisfactory. Off-diagonal constants not included were examined, found to be insensitive or to have undesirably high dispersions, and were constrained to zero. The final values for the symmetry force constants, symmetry compliance constants obtained by inverting the $F$ matrices, and the derived stretching valence constants are shown in Table 4. Valence force constants involving the angles could not be obtained from the symmetry constants because of the redundancies.

Comparison of the constants in Table 4 with those from the previous work [5] can only be approximate in view of the revised assignments, differences in the interaction constants used in the potential functions, and the fact that frequencies for the deuterated species were included in the present work. Nevertheless, the agreement noted is reasonable. The value for the force constant of greatest interest, that for the dative bond, was found to be $2.31 \mathrm{mdyn} \AA^{-1}$ in the present work compared to the previously reported 
Table 4. Force and compliance constants for trimethylphosphine-gallium trichloride symmetry constants

\begin{tabular}{|c|c|c|c|c|c|}
\hline \multicolumn{3}{|c|}{$A$, Class } & \multicolumn{3}{|c|}{$E$ Class } \\
\hline Indices & Force & Compliance & Indices & Force & Compliance \\
\hline 1,1 & 4.763 & 0.210 & 16,16 & 4.388 & 0.252 \\
\hline 2,2 & 4.922 & 0.203 & 17,17 & 4.796 & 0.209 \\
\hline 3,3 & 0.524 & 1.908 & 18,18 & 4.934 & 0.203 \\
\hline 4,4 & 0.547 & 2.248 & 19,19 & 0.631 & 1.809 \\
\hline 5,5 & 0.255 & 5.726 & 20,20 & 0.639 & 2.046 \\
\hline 6,6 & 3.381 & 0.381 & 21,21 & 0.318 & 3.581 \\
\hline 7,7 & 2.310 & 0.567 & 22,22 & 0.856 & 1.373 \\
\hline 8,8 & 2.086 & 0.487 & 23,23 & 0.480 & 2.088 \\
\hline 9,9 & 2.186 & 0.648 & 24,24 & 3.733 & 0.351 \\
\hline 10,10 & 0.810 & 1.617 & 25,25 & 1.626 & 0.615 \\
\hline 4,6 & -0.576 & 0.401 & 26,26 & 0.542 & 2.011 \\
\hline 5,6 & 0.142 & -0.298 & 27,27 & 0.429 & 2.394 \\
\hline 5,9 & 0.399 & -1.044 & 28,28 & 0.091 & 11.469 \\
\hline 6.8 & -0.287 & 0.052 & 29,29 & 0.590 & 1.908 \\
\hline 7,10 & 0.664 & -0.165 & 30,30 & 0.824 & 1.279 \\
\hline \multirow[t]{2}{*}{4,5} & - & -0.315 & 16,19 & 0.502 & -0.207 \\
\hline & & & 19,22 & -0.125 & 0.300 \\
\hline \multirow{2}{*}{\multicolumn{3}{|c|}{ Valence stretching force constants }} & 20,24 & -0.748 & 0.410 \\
\hline & & & 21,22 & -0.179 & 0.772 \\
\hline \multicolumn{2}{|c|}{$\mathrm{P}-\mathrm{Ga}$ Stretch } & 2.310 & 23,24 & 0.047 & -0.034 \\
\hline \multicolumn{2}{|c|}{ Ga Cl Stretch } & 1.780 & 26,28 & 0.028 & -0.633 \\
\hline \multicolumn{2}{|c|}{ P-C Stretch } & 3.615 & 26,29 & 0.142 & -0.507 \\
\hline \multicolumn{2}{|c|}{ C-H Stretch } & 4.794 & 27,28 & -0.032 & 0.856 \\
\hline \multirow{3}{*}{\multicolumn{2}{|c|}{ C $\mathbf{H}^{\prime}$ Stretch }} & 4.652 & 29,30 & 0.152 & -0.353 \\
\hline & & & 19,21 & - & 0.169 \\
\hline & & & 26,21 & - & 0.094 \\
\hline
\end{tabular}

value of 2.01 mdyne $\AA^{-1}$ [5]. Other values in the literature for the $\mathrm{Ga}-\mathrm{P}$ dative bond constant (e.g. Ref. [7]) range considerably lower, from abut $0.9-2.0 \mathrm{mdyn} \AA^{-1}$. The bond in the gallium trichloride adduct thus appears to be of intermediate strength and not as strong as the dative bonds in adducts of the first row elements despite the fact that gallium trichloride is a good acceptor.

The $\mathrm{Ga}-\mathrm{Cl}$ valence stretching constant from Table $4\left(1.78\right.$ mdyn $\left.\AA^{-1}\right)$ is quite close to that of 1.75 mdyn $\AA^{-1}$ in the previous work [5] and is substantially less than in free $\mathrm{GaCl}_{3}$ [5], a behavior which is usually fond in Lewis complexes. The valence constant for the $\mathrm{P}-\mathrm{C}$ stretch reported here, $3.615 \mathrm{mdyn} \AA^{-1}$, is comparable to the value of $3.44 \mathrm{mdyn} \AA^{-1}$ from Ref. [5] and also is not that much different than the values for the same bond in trimethylphosphine oxide, sulfide and selenide, the range there being from 3.49-3.29 mdyn $\AA^{-1}[19]$.

The calculated potential energy distributions, for the most part, showed that the vibrational modes agreed well with the qualitative descriptions given in Table 3 . However, in the $\mathrm{A}_{1}$ class, the $\mathrm{Ga}-\mathrm{P}$ and $\mathrm{Ga}-\mathrm{Cl}$ stretching modes showed considerable mixing as did the methyl rocking mode and the $\mathrm{PC}_{3}$ deformation. In the $E$ class, substantial mixing was present between the $\mathrm{CH}_{3}$ rock and one of the asymmetric $\mathrm{CH}_{3}$ deformations, between the $\mathrm{PC}_{3}$ rock and the $\mathrm{PC}_{3}$ deformation, and between the $\mathrm{GaCl}_{3}$ deformation and the $\mathrm{GaCl}_{3}$ rock.

In conclusion, it should be noted that the principal molecular deviation from $C_{3 v}$ symmetry in the actual crystal, based on the X-ray structure, occurs for the methyl groups. In the model used for the calculations, it was assumed that three hydrogen atoms were situated in the molecular symmetry planes and pointed towards the chlorine atoms. Changing the conformation of the methyl groups did alter the fit of the observed frequencies and changed the values of some of the force constants. The most satisfactory results, however, are those presented. 


\section{REFERENCES}

[1] P. H. Laswick and R. C. Taylor, J. Molec. Struct. 34, 197 (1976).

[2] J. C. Carter, G. Jugie, R. Enjalbert and J. Galy, Inorg. Chem. 17, 1248 (1978).

[3] I. R. Beattie and G. A. Ozin, J. Chem. Soc. 2373 (1968).

[4] A. Balls, N. N. Greenwood and B. P. Straughan, J. Chem. Soc. 753 (1968).

[5] J. R. Durig and K. K. Chatterjee, J. Molec. Struct. 81, 167 (1982).

[6] M. J. Taylor and S. Riethmiller, J. Raman Spectrosc. 15, 370 (1984).

[7] M. J. Tuylor, D. S. Bohle and S. Riethmiller, J. Raman Spectrosc. 15, 393 (1984).

[8] W. L. Jolly (Editor), Inorganic Syntheses, Vol. XI, p. 126. McGraw-Hill, New York (1968).

[9] L. J. Bellamy, The Infrared Spectra of Complex Molecules, 2nd Edn, pp. 315-317, Sect. 18.3. Methuen, London (1958).

[10] D. L. Black, Dissertation, The University of Michigan (1971).

[11] H. Rojhantalab, J. W. Nibler and C. J. Wilkins, Spectrochim. Acta 32A, 519 (1976).

[12] P. J. D. Park and P. J. Hendra, Spectrochim. Acta 24A, 2081 (1968).

[13] D. C. McKean and G. P. McQuillan, Spectrochim. Acta 39A, 293 (1983).

[14] T. Takenaka and R. Gotoh, Bull. Inst. Chem. Res. Kyoto Univ. 40, 272 (1962).

[15] G. Bouquet and M. Bigorgne, Spectrochim. Acta 23A, 1231 (1962).

[16] R. C. Taylor, R. W. Rudolph, R. J. Wyma and V. D. Dunning, J. Raman Spectrosc. 2, 175 (1974).

[17] J. D. Odom, K. K. Chatterjee and J. R. Durig, J. Phys. Chem. 84, 1843 (1980).

[18] T. R. Stengle and R. C. Taylor, J. Molec. Spectrosc. 34, 33 (1970).

[19] F. Watari, E. Takayama and K. Aida, J. Molec. Struct. 55, 169 (1979). 